\title{
LA TIRANÍA DE LA BELLEZA, UN PROBLEMA EDUCATIVO HOY. LA ESTÉTICA DEL CUERPO COMO VALOR Y COMO PROBLEMA
}

The tyranny of the beauty, an educational problem. The aesthetics of the body like a value and a problem

La tyrannie de la beaute, un probleme educationnel. L'esthétique du corps comme valeur et comme problème

Enrique GERVILLA CASTILLO

Universidad de Granada. Facultad de Ciencias de la Educación. Departamento de Pedagogía. Campus Universitario Cartuja. 18071 Granada.

Correo-e: egervill@ugr.es

Fecha de aceptación definitiva: marzo de 2003

BIBLID [(1130-3743) 14, 2002, 185-206]

RESUMEN

Un problema actual, propio de la sociedad de consumo, es el culto al cuerpo y a su valor estético. La obsesión por el cuerpo perfecto ha conducido, especialmente a grupos de jóvenes, a una tiranía de la belleza. Ello dificulta en unos casos, e impide en otros, la coexistencia de otros valores de mayor urgencia y necesidad en la formación humana, alterando, así, el orden vivencial de la jerarquía axiológica según la fuerza y la altura.

Tal situación, demanda una respuesta desde la educación, por cuanto ésta, no sólo pretende incorporar valores a la existencia personal, sino una incorporación acorde con el desarrollo integral y armónico del ser humano en cuanto humano. Para ello, es necesario persuadir, convencer y no vencer - mediante la reflexión crítica 
del problema, la apreciación y el esfuerzo- para impulsar la decisión de la voluntad, más aún en situaciones ambientales adversas.

Palabras clave: tiranía estética, belleza corporal, jerarquía valores, educación integral.

\section{SUMMARY}

A current problem, characteristic of the customer society, is the cult to the body and its aesthetic value. Obsession for the perfect body has driven, especially to groups of young people, to a tyranny of beauty. This make more difficult it in some cases, and impedes otherwise, the coexistence of other more urgency and necessity values in the human formation, altering, in this way, the vivencial order of the axiologic hierarchy according to the strengh and height.

This situation, demands an answer from education, becouse of this, it doesn't only seek to incorporate values to personal existence, but an incorporation in agreement with the integral and harmonic improvement of the human being as a human. For this, it is necessary to persuade, to convince and not to conquer - by means of the critical reflection of the problem, appreciation and effort-- to impel the decision of the will, stiller in adverse environmental situations.

Key words: aesthetic tyranny, corporal beauty, hierarchy values, integral education.

SOMMAIRE

Un problème actuel, propre de la société de la consommation, est le culte au corps et sa valeur esthétique. L'obsession pour le corps parfait a conduit, surtout à des groupes de jeunes, à une tyrannie de la beauté. Ceci fait difficile dans quelques cas, et empêche dans d'autres, la coexistence d'autres valeurs plus urgents et nécessaires dans la formation humaine, en changeant l'ordre vivenciel de la hiérarchie axiologique d'après la force et la hauteur.

Une telle situation demande une réponse éducationnelle, étant donné que l'éducation ne cherche pas seulement à incorporer des valeurs à l'existence personnelle, mais aussi à ce que cette incorporation soit faite en harmonie avec le dévéloppement plein de l'être humain en tant qu'humain. Pour atteindre cet objectif il est nécessaire de persuader, convaincre et pas vaincre -à travers la reflexión critique du problème, l'estimation et l'effort- pour impulser la décision de la volonté, encore plus dans un environnement si difficile.

Mots clef: tyrannie esthétique, beauté corporelle, hiérarchie valeurs, éducation intégrale. 


\section{INTRODUCCIÓN}

Los diversos momentos históricos son portadores de un conjunto de valores, y también de antivalores, generadores de una serie de inquietudes, preguntas y problemas, a los que la educación ha de dar respuesta. Las circunstancias físicas, y sobre todo humanas, constituyen una fuerza tal en la configuración de los humanos que los tratados de educación denominan "educabilidad histórica".

El tema que nos ocupa, y también preocupa, es fruto de circunstancias ambientales, de un impacto tan fuerte en nuestra sociedad, sobre todo entre los jóvenes, que dificulta, y hasta impide, el desarrollo armónico de la persona. Hoy la estética del cuerpo, el valor de la belleza corporal, se ha impuesto con gran poder sobre otros valores de la persona, que éstos, frecuentemente, quedan anulados o minusvalorados de tal modo que bien podemos hablar de dictadura o tiranía de la belleza. La obsesión por el cuerpo perfecto es un grave problema para muchos padres e hijos, como manifiestan las investigaciones más recientes. Así, la preocupación por la anorexia y la bulimia alcanza ya al 25,4\% de los chicos y al $56 \%$ de las chicas (Pérez y Cánovas, 2002, 96-97). Los medios de comunicación social son el cauce fundamental de este conocimiento y, en buena parte, la causa del problema ${ }^{1}$. Vivimos tiempos en los que la moda está más en la apariencia que en el ser, llegado incluso a sufrir, por el aspecto físico, sudor y lágrimas para ser bellos.

La educación, caminante inseparable de la persona y de la sociedad, ha de conocer para hacer, saber para criticar, reflexionar, justificar, cambiar..., dar respuesta a las preguntas, y posibles soluciones a los problemas del ser humano y de la sociedad, pues una educación "ignorante", o bien anclada en el pasado, sin pretensión de cambio, de mejora..., deja de ser educación eficaz para el hombre de hoy.

Las siguientes páginas se ocupan de este problema. En primer lugar exponemos la importancia actual del cuerpo, sujeto y objeto de cultura, cuya fuerza unilateral ha originado la dictadura estética y el culto al cuerpo. Seguidamente, tratamos de la belleza corporal, como valor y como conflicto, en el conjunto de valores de la persona, atendiendo a la fuerza y altura de los mismos. Y finalmente, reconociendo la importancia del valor estético del cuerpo, analizamos críticamente la oposición entre la educación integral y la tiranía de la belleza, ofreciendo algunas orientaciones educativas en las actuales circunstancias.

\section{LA CULTURA DEI CUERPO}

El cuerpo goza hoy de una importancia especial y, por ello, generador de cultura. Desde que el ser humano es tal se ha ocupado, y también preocupado, de su cuerpo como parte esencial de su ser. Lo cambiante, a través de los siglos, ha sido

1. El 79,7\% da como razón más importante de la anorexia y bulimia lás respuestas a los mensajes de los medios de comunicación sobre la imagen del cuerpo (Pérez y Cánovas, 2002, 96-97). 
el sentido y las valoraciones asignadas al mismo: desde la concepción platónica del cuerpo cárcel o tumba del alma, hasta la internacional canción dale a tu cuerpo alegría Macarena, el cuerpo siendo el mismo, no ha sido lo mismo.

Esta pluralidad de valoraciones ha generado culturas diversas, y hasta antagónicas, acorde con la etimología latina del vocablo cultura: colo, colere, verbo que significa cultivar o cuidar. Cultivo y cuidado del cuerpo siempre realizado con una intención valiosa, por cuanto la cultura siempre tiene como referente el amplio y complejo mundo de los valores, unos u otros, según el momento histórico. Cultura, pues, puede significar cualquier cosa material, acontecimiento o acción, que el ser humano realiza con alguna finalidad valiosa o interesada para alguien; cuanto los humanos hacemos y producimos, al proyectar el universo simbólico en el mundo físico, de modo intencional acorde con un sentido y orientación. La cultura, pues, en cuanto valoración pluriforme de la vida, la vive e interpreta el científico y el hombre de la calle, el profesor y el obrero. Cada cual a su modo, acorde con sus necesidades y sentidos, por lo que, junto a la cultura de los intelectuales, existe también la cultura de la calle o cultura popular, la que vive la gran mayoría del pueblo, que además de ser cultura, es la cultura más vivida ${ }^{2}$.

Hoy, a comienzos del siglo xxi, el cuerpo es sujeto y objeto de cultura, si bien, a diferencia de los siglos precedentes, con una finalidad propia, acorde con la sensibilidad cambiante de este momento. Las manifestaciones artísticas de la estética corporal son constantes en el cine, en el mundo de la canción y de la moda, en los presentadores/as de TV, en los anuncios de productos light, cosméticos, dietas, cirugía estética, etc. Cultura hoy vivida con tal intensidad que se convierte, para muchos, en un verdadero sujeto y objeto de culto.

\section{El CUlto Al CUERPo}

La sociedad actual manifiesta un claro culto a la belleza del cuerpo, por cuanto ésta, en buena parte, condiciona, y hasta determina, el placer, el éxito, amistades, sexo, etc. Hoy quienes gozan de "buena presencia" poseen, y sólo por ello, mayores posibilidades laborales, de relaciones humano-afectivas y de aceptación social. Un valor, sobre todo para los jóvenes, y frecuentemente también para mayores, de una importancia tal que llega a convertirse en un super-valor o valor primero. De este modo, subordinan a este "dios" la comida, el descanso, el vestido, el placer, el dinero... Todo, o casi todo, al servicio de la fuerza de su belleza. Nuestra sociedad así lo demanda, pues uestar al lorom es manifestar, más que el ser, el modo de ser según el modelo estético socialmente reconocido, asociado a la dualidad delgadezjuventud.

2. En consecuencia, pues, ni el hombre, ni los pueblos, desde la antigüedad hasta la actualiclad, pueden vivir sin cultura, por cuanto el ser humano es un animal inserto en redes de significáción y es, justamente, este conjunto de redes lo que constituye el horizonte significativo a partir del cual existimos. 
La belleza — como comenta Lipovetsky - se ha democratizado al alcanzar sus cuidados a todas las capas de la sociedad, convirtiéndose los productos de belleza en artículos de consumo corriente, en un lujo al alcance de todos (Lipovetsky, 2000). La belleza es, pues, un valor generalizado y un "culto" para muchos. Tener un físico agradable se ha convertido en una "obligación", pues ello supone prestigio, seguridad y superioridad, aunque, a veces, se alcance a costa del sacrificio de otros valores más humanizantes. Hoy el narcisismo ha quedado asociado a la apariencia corporal, a la belleza, a la satisfacción personal, al triunfo, y a la autoestima. Somos voraces consumidores del cuerpo delgado, joven y sensual. Nunca el cuerpo ha influido tanto en el yo, y en el autoconcepto. No se trata del cuerpo en su totalidad, sino de su apariencia física, silueta, talla, color... tal como exhiben los modelos encarnados en las personas sobrevaloradas socialmente: deportistas, famosos, top-models, actores y actrices, etc.

Y cuando el propio cuerpo no es acorde con los modelos vigentes en la sociedad, los avances de la ciencia se ponen a su servicio, al servicio del cuerpo perfecto, a la medida. Se trata de corregir la obra de la naturaleza, de vencer los estragos ocasionados por el paso del tiempo, de sustituir el cuerpo recibido por un cuerpo construido (Lipovetsky, 2000). Para ello la cirugía estética ofrece unos resultados rápidos y espectaculares: láser, implantes mamarios de silicona, trasplantes de órganos, correctores, prótesis de todo tipo, injertos, etc. Hoy la ciencia consigue el cuerpo que queremos, a gusto del consumidor. Ya el ser humano no contempla su físico como algo definitivo e inalterable, pues los cambios de aspecto corporal están a la orden del día: calvicie, michelines, nariz, orejas, reducciones y alargamientos...

Los institutos de belleza, décadas atrás casi inexistentes, ofrecen soluciones a todos los problemas relacionados con la estética. La demanda es tal que ha surgido la nueva profesión de esteticista. Sus funciones y futuro aparecen en cualquier medio de comunicación ${ }^{3}$. Ya pasó el tiempo en que "el hombre y el oso cuando más feo mas hermoso". Hoy el cuerpo, "la percha", en mayor o menor grado, se encuentra asociado a todo o a casi todo. Vivimos en una época tan sensual que sólo los cuerpos guapos son válidos para vender coches, detergentes, viviendas, productos alimenticios, etc. Una imagen, hoy más que nuca, vende más que mil palabras. La ética ha cedido su valor, en buena parte, a la estética, y lo justo al gusto. Antes los sacrificios, las mortificaciones y la autodisciplina eran los tributos

3. En uno de ellos leemos lo siguiente: "Esteticista, una profesión para toda la vida. Conviértete en una profesional de la belleza. La imagen personal tiene cacla día más importancia. El cuidado de nuestro aspecto físico, y mantener a lo largo de los años un rostro y un cuerpo agradables, forman parte de nuestra cultura. Las expectativas de vida aumentan. Las personas tienen la posibilidad de disfrutar y sentirse jóvenes durante más tiempo. Por eso la profesión de esteticista es una profesión para toda la vida. Y por eso ofrece tantas satisfacciones a las personas que la ejercen. Aprenderás a aplicar los tratamientos más usuales en un Instituto de Belleza: masajes faciales y corporales, limpieza de cutis, peeling, depilaciones... Sabrás realizar manicuras y pedicuras. Dominarás las técnicas de maquillaje y desmaquillaje. Aprenderás a diferenciar las distintas afecciones de la piel y sus tratamientos: acné, celulitis, obesidad, afecciones de cabello..." (El Semanal TV, 17 enero, 1999, 15). 
que los humanos habían de rendir a la divinidad, una exigencia moral para mantenerse puros y dignos. Hoy, para muchos, la búsqueda de la perfección moral ha sido sustituida por la perfección corporal.

Otro tanto puede afirmarse de la moda. El vestido, ya no sólo cumple la función de protección y abrigo, sino también de identidad personal y de belleza. La ropa puede cubrir y destapar, manifestar y ocultar, poner de relieve, insinuar u ocultar cualquier parte del cuerpo. Cada una de estas funciones cambia según el tiempo, el espacio y la cultura. La moda encuentra aquí su fuerza seductora e impositora. Hoy, acorde con los nuevos valores, la moda adquiere connotación joven, debe expresar un estilo de vida emancipado, libre de obligaciones y de normas impuestas, inconformismo, humor e individualidad. Más que la perfección, preocupa la espontaneidad, originalidad, impacto inmediato o manifestar la ruptura con la generación precedente. Aparentar menos edad importa mucho más que exhibir un determinado rango social.

El vestido es, pues, para muchos un punto crucial de referencia estética. Nuestro modo de vestir es esencialmente una forma de relación humana, de imitación, de distinción social y de diferenciación individual, en el que el presente y, a veces, sólo por presente (novedad, actualidad, moda) justifica una determinada indumentaria: "Todo nuevo, todo bueno". Todos los estilos y todos los materiales pueden tener legitimidad en la moda: lo desalinado, lo desgarrado, lo desconocido, lo descuidado, lo usado, lo deshilado. Jeans desteñidos, jerséis deformados, zapatillas de tenis gastadas, prendas retro, grafismos de cómics en camisetas, etc., forman aparte de la indumentaria de los jóvenes ("look mendigo"). Lo nuevo debe parecer usado y lo estudiado espontáneo, lo pulcro ha cedido su lugar a lo paupérrimo. Es el momento en que la moda se burla de la moda y la elegancia de la elegancia. La gente más que ser elegante quiere seducir. Lo importante es ser uno mismo, estar cómodo, agradar, sorprender, ser joven ${ }^{4}$. Nos hallamos, pues, ante una nueva estética en la que confluyen tantos estilos y se mezclan tantas variedades, que podemos afirmar que "todo vale» en algún sentido, aunque no todo valga con la misma fuerza para todos.

4. "El traje del domingo" ha desaparecido y el rico atuendo de las clases superiores se ha eclipsado. El individualismo actual es, ante todo, la eliminación del simbolismo jerárquico en favor de la libertad, el placer y la comodidad. En este sentido, los vaqueros — por su símbolo y propiedades- ocupan, en la estética actual, un lugar muy privilegiado: es una prenda sufrida, soporta desgastes, desgarros y deslavados, no exige planchado ni limpieza meticulosa, resalta la forma del cuerpo y pone de relieve las caderas, las piernas y las nalgas, posee connotaciones sexy y anticonformistas (en sus origenes fue adoptado por los jóvenes reacios a las normas convencionales), ha sido ilustrado por la música rock, a finales de los años sesenta representaba la contestación generalizada y la contracultura, se distancia del vestir aristocrático para imitar el mundo del trabajo... De aquí que se haya convertido en una prenda unisex que, para acentuar más estos aspectos, se le añaden piezas de colores, remiendos, se les hacen rotos y añaden flecos. Su uso es ya tan imprescindible que, incluso en los momentos de "etiqueta" (conservadurismo), se adorna con la corbata y la chaqueta. 
Los medios de comunicación social o mass-media son actualmente los cauces más influyentes de reproducción de una estética corporal, por cuanto explican, crean y reproducen valorativamente patrones de conducta y estilos de vida, legitimando comportamientos de personas, grupos e instituciones. Son "medios privilegiados" de creación y transmisión de valores o antivalores y, por tanto, de innovación, cambio o potenciación de una determinada cultura, mentalidad o culto $^{5}$. Hoy el mundo de la imagen, y singularmente la TV goza de un atractivo especial. Las generaciones jóvenes son cada vez menos lectoras y cada día más televisivas. La fuerza seductora de la TV reside en que su comunicación se realiza desde el marco del placer, de la renovación y de la distracción. Todas sus emisiones deben adoptar la perspectiva del ocio. El objetivo fundamental es "enganchar" a la mayor parte del público mediante la tecnología del ritmo rápido y placentero. Seducir es lo primero. Baste observar los presentadores/as de informativos, concursos, y sobre todo de publicidad: cuerpos perfectos, jóvenes, bellos, sexys, simpáticos, atractivos, encantadores, de voz tranquilizadora, etc. Su poder de seducción es tal que se hace difícil resistir a su fuerza, pues en un mismo mensaje, directa o indirectamente, junto a la belleza y utilidad del producto, se ofrece también la distinción y pertenencia a un estatus social. De este modo, más o menos conscientemente, esta situación conduce a un materialismo hedonista y narcisista sin límites, en el que tener, gozar y aparentar, vale mucho más que el ser.

Todo ello genera un consumismo desmesurado sobre el cuerpo, cuyos productos no siempre se adquieren por su valor de uso (necesidad del objeto en sí), sino que, frecuentemente, lo hacemos por "su valor de cambio", es decir, en razón del prestigio, de la belleza, del estatus o del rango social que nos confiere. Como observó J. Baudrillard, por encima de la satisfacción espontánea de las necesidades, hay que reconocer en el consumo un instrumento de jerarquía social. Tal artículo asegura prestigio, calidad de vida, seguridad, personalidad o independencia. No siempre se consume un objeto por sí mismo, según su valor utilitario, sino como signo que nos distingue. Esta cultura del simulacro termina alumbrando "estrategias fatales": los objetos, privados de su esencia y utilidad, se convierten en esencias vacías y fascinantes, ante cuya seducción no se resiste la persona. La astucia del objeto acaba imponiéndose al sujeto (Baudrillard, 1992). De aquí que una determinada marca o etiqueta en zapatillas, blusa o pantalón diga, a veces, más que la utilidad de la misma prenda en sí. Por eso, ahora las marcas se exhiben en lugares visibles, puede ser la señal de clasificación y pertenencia a la beautiful people. Se trata de un proceso de producción de los "valores signo", cuya función es manifestar las diferencias sociales.

5. "Valores, por ejemplo, como el esfuerzo, el sacrificio, el ahorro, la autoridad o la castidad - como escribe Lipovetsky - ya no inspiran respeto, e invitan más a la sonrisa que a la veneración" (LIPOVETSKY, 1990, 162). 
Este culto al cuerpo ha originado todo un mercado de negocios, en el que se mueven grandes cantidades de dinero, como nunca en las épocas precedentes. En España es la segunda industria después del armamento ${ }^{6}$. El cuerpo es objeto de comercio en la moda, en los cosméticos, cremas, dermoprotectores, en los gimnasios, pistas de squash y paddle para ejecutivos, aerobic, maratones, productos dietéticos, revistas, herbolarios... La industria "pro-adelgazamiento" posee hoy una variedad de propaganda y una red organizada, cuyos libros, productos light, mensajes - al margen de su veracidad y supuesta inocuidad-ocasionan grandes beneficios. El cuerpo es así, y a un mismo tiempo, moda cultural y negocio empresarial.

La publicidad, en sus distintos medios y modalidades, presente hoy en todos los grandes medios, alcanza su objetivo consumista "atacando" por sorpresa y suavemente, invitando provocativamente, pero sin agredir. Para ello, agita el deseo de renovación permanente, se desvincula de lo tradicional, poetiza el producto e idealiza la marca, sacraliza lo nuevo y muestra el look social. A sus mensajes se unen cuerpos bellos y eróticos, situaciones placenteras de confort, virilidad o feminidad, juventud, sonrisa y dinamismo... La seducción va más al sentimiento y a las resonancias estéticas que al razonamiento intelectual y a la justificación de la excelencia objetiva del producto. Se sitúa, pues, más allá de lo verdadero y lo falso, con cierto sentido humorístico y fruitivo. Slogans que no dicen nada, más que cambiar, aparentar, vestir de un modo u otro, comprar sin importar demasiado el qué; basta que se lleve, que sea de hoy, actual. La publicidad funciona así como estética de la comunicación: se dirige a la vista, a la emoción, a la belleza, a la seducción; desustancializa el producto en pro de la novedad, y la pasión por lo nuevo hace que lo efímero lo invada todo. Esta espiral de lo imaginariamente bello es la respuesta a la demanda del individualismo hedonista y emocional.

Hoy la publicidad lo invade todo, sin que podamos escapar totalmente a su influencia. Esta avidez económica aprovecha las inclinaciones estético-corporales vigentes para vender productos adelgazantes, de moda y juveniles. Ello contribuye, aún más, al mantenimiento y arraigo de tales deseos haciendo, directá o indirectamente, atractivo el producto, asociándolo a un cuerpo deseable. El producto se acompaña con imágenes visuales o/y palabras que describen el ideal del posible cuerpo: cara, ojos, labios, color de la piel, cuerpo semidesnudo...?

6. Documentos $T V$, de la segunda cadena, emitió el miércoles 5 de febrero un reportaje, bajo el título "Cuerpo a la carta", en el que se ofrecía este dato, junto a otros bastantes alarmantes, en relación a la belleza corporal.

7. Es importante constar al efecto la creación en el Reino Unido de la ASA (Advertising Stanclard Authority), organismo destinado a velar por la decencia, verdad, legalidad y responsabilidad de la publicidad. 


\section{LA BELLEZA COMO CASTIGO}

La fuerza de la belleza es tal que, a veces, llega a convertirse en patología. Una modalidad del culto al cuerpo - aunque en apariencia contraria- es la privación y el castigo. La anorexia y la bulimia son coincidentes en el rechazo e insatisfacción del propio cuerpo, pues ambas comparten una misma ansiedad por la delgadez y el miedo por aumentar peso ${ }^{8}$. La imagen del cuerpo es tan valorada que es necesario mortificarla para que, estéticamente, sea lo que socialmente debe ser.

En ambos trastornos los factores socioculturales son determinantes, pues en nuestra sociedad ser obeso es un auténtico castigo, por el rechazo, más o menos manifiesto, de los demás. El anhelo de delgadez, la insatisfacción del propio cuerpo y la práctica de dietas restrictivas suelen ser elementos constantes, especialmente en la pubertad y en la adolescencia. La valoración real del propio cuerpo -imagen mental-y la comparación con el modelo social vigente -ideal estético- provoca una tensión y ansiedad en no pocos jóvenes. El anhelo de conseguir este ideal se realiza mediante el castigo del propio cuerpo, sometiendo éste a toda clase de sacrificios y restricciones, pues se es consciente que la persona físicamente atractiva recibe más elogios, y posee una mayor aceptación social, que otra no atractiva sólo por su imagen.

Esta fuerza es tal que varios estudios científicos constatan el deseo, frecuentemente desmesurado, de no pocos jóvenes y adolescentes por el cambio de su cuerpo. Así, en el V Congreso estatal de Asociaciones contra la Anorexia y Bulimia (San Sebastián, 2002), Josep Toro, psiquiatra y responsable de la unidad de trastornos alimenticios del Clínico de Barcelona, afirmaba que el 18\% de las niñas de Barcelona de 9 años hacen régimen, y que ya, a los 5 años, el niño sabe que si está delgado tiene mayor aceptación. La persona, de este modo, intenta recuperar la juventud a base de perder kilos, pues es consciente que una determinada apariencia física está asociada al éxito, prestigio y aceptación social.

La preocupación constante por la línea puede causar alteraciones afectivas, de la conducta, trastornos de ansiedad y graves complicaciones médicas, elevando el

8. La anorexia nerviosa es un trastorno del comportamiento alimentario caracterizado por una fuerte pérdida de peso corporal, habitualmente fruto de la decisión voluntaria de adelgazar. Para ello se reduce el consumo de alimentos, se ingieren indebidamente laxantes, se autoprovocan vómitos, se realiza un desmesurado ejercicio físico, se consume diuréticos, etc. Tal enfermedad, de la que generalmente no se tiene conciencia, es mayoritariamente sufrida entre los jóvenes (14-18 años). Éstos experimentan un intenso miedo al aumento de peso, a pesar de su progresiva disminución distorsionando, así, su imagen corporal, su autoimagen.

La bulimia es igualmente un trastorno del comportamiento alimentario, en el que la persona afectada ingiere cantidades de alimento superiores a lo normal, sin posibilidad alguna de control. Los atracones se unen a prácticas destinadas a compensar la silueta corporal: vómitos autoinducidos, laxantes, diuréticos, etc. Esta sensación provoca restricciones alimentarias y ayunos compensatorios, que asemeja la bulimia con la anorexia, así como la preocupación desmesurada por el peso y la influencia de éste en la autoestima (TORO, 1996, 7-11). 
riesgo de anorexia. Muchas jóvenes y adolescentes empiezan a enfermar al no encontrar ropa de su talla en las tiendas juveniles y tener que recurrir a las de señoras. Ante esta situación, el Grupo Socialista, en el año 1999, presentó dos proposiciones en el Congreso para regular el tallaje. Y, con este mismo propósito, el Salón Gaudí se ha comprometido a no aceptar modelos con talla inferior a 40.

Tales hechos ponen de manifiesto unas de las paradojas más graves e inmorales de nuestro tiempo, pues mientras gran parte de la humanidad muere de hambre, o bien se nutre de modo insuficiente por falta de alimentos, otro sector del mundo, gracias a su opulencia, pasa también hambre para adelgazar y así adecuar su imagen a los modelos de belleza vigentes?.

En síntesis, pues, salud, belleza y moral, tres valores humanos en conficto - como hemos indicado- que demandan una necesaria, y hasta urgente, clarificación en orden a la construcción humana, personal y social.

\section{LA FUERZA Y LA ALTURA DE LOS VALORES}

Hoy resulta evidente que el ser humano no puede vivir sin valores, unos u otros, pues la carencia total de valores, además de imposible, conllevaría la muerte del ser humano en cuanto humano, y, por lo mismo, también de la educación. Lo discutible, por tanto, no son los valores sino qué valores y qué orden jerárquico, pues, aunque teóricamente puedan existir valores sin relación alguna con la persona, sin embargo, bajo el punto de vista de la construcción humana, los valores son para alguien o no son para nadie. De aquí que expresiones tales como "vivimos en una sociedad sin valores", o bien "se han perdido los valores", o "la juventud de hoy carece de valores", etc., además de falsas, manifiestan un radicalismo e inmovilismo axiológico. Quienes tales afirmaciones sostienen sólo pueden afirmar que la sociedad o la juventud actual carece cle "sus valores", o de los valores vigentes hace años entre nosotros, pero no la ausencia total de valores.

El destino del ser humano es humanizarse, desplegar al máximo todas sus potencialidades, incorporando valores a su existencia. En palabras de Maslow,

el hombre muestra en su propia naturaleza un impulso hacia un Ser cada vez más pleno, hacia una realización cada vez más perfecta de su humanidad, en el mismo sentido científico y natural en el que clecimos que una bellota "apremia hacia" su conversión en

9. Ello en nuestro mundo occidental, pues sabemos que las mujeres de Samoa engordan notablemente en cada embarazo para ser bien vistas por aquella sociedad. Y en la Edad Media el cuerpo femenino debía ser corpulento y el vientre redondeado, símbolo de la fertilidad. La mujer gruesa era el modelo. Ello debe entenderse en un contexto social en el que engordar era signo de riqueza y de salud. El aprecio de la riqueza implicaba rechazo a la delgadez, esto es, la huida del hambre, de la enfermedad y de la pobreza. Así a la aristocracia dirigente se la denominaba popolo grasso, mientras que las clases populares se conocían como popolo magro (CONTRERAs, 1993). 
encina, o en el que observamos que un tigre "presiona hacia" su realización como tigre, o un caballo hacia su realización como equino (Maslow, 1998, 202).

Esta realización o impulso hacia el desarrollo personal, nacido de la inmadurez humana, es siempre es una tarea personal e ineludible, realizada mediante la opción vivencial por unos u otros valores, acorde con la configuración de la singularidad personal. Tal incorporación, al igual que el crecimiento corporal, ha de realizarse de modo jerárquico, ordenado y armónico, si bien esta jerarquía u orden preferencial es analíticamente diverso según distintas antropologías y autores. Así, para Lavelle los valores se ordenan atendiendo al hecho del ser humano arraigado en el mundo, pero con la posibilidad de distanciarse de él para contemplarlo y trascenderlo. Ello conduce a tres planos jerárquicos de valores correspondientes 1) al hombre en el mundo, por pertenecer al él como ser inmerso en la naturaleza: valores económicos o utilitarios y afectivos (dolor, placer); 2) al hombre ante el mundo, como espectador o contemplador de la naturaleza: valores intelectuales y estéticos; 3) y al hombre sobre el mundo en cuanto trascendente o elevado sobre la naturaleza: valores morales y religiosos (Lavelle, 1995, 385). Para J. M. a Méndez, los valores fundamentales de primer orden son cuatro: lo útil, lo bueno, lo bello y lo santo, o sea, los estratos valiosos de: lo económico, lo ético, lo estético y lo ascético (Méndez, 1985, 137138). M. Scheler, por su parte, según la altura o superioridad, distingue los siguien-

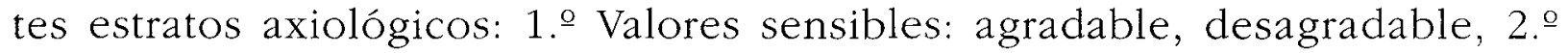
Valores vitales: salud, prosperidad, bienestar, 3. Valores espirituales: bello, justo, verdadero, y 4. Valores religiosos: Dios, santo, culto (Scheler, 1941, 155-156).

El dinamismo de los valores básicos impulsa al ser humano hacia los niveles superiores, dado el inconformismo y la presión de la naturaleza hacia la plenitud: "La satisfacción de una necesidad básica seguirá esforzándose, ya que la satisfacción de una necesidad básica abre las puertas de la conciencia al predominio de una necesidad superior" (Maslow, 1998, 194). Así, el amplio conjunto de valores humanos se presenta para su realización de modo desigual, pues unos atañen a las necesidades básicas de supervivencia, y otros satisfacen carencias superiores propias y exclusivas de los humanos. De aquí que, aunque todos los valores son importantes, no todos lo sean en el mismo sentido, ni con la misma necesidad, pues unos son más urgentes y comunes: los valores inferiores (comida, salud, higiene, descanso), y otros son más nobles y propios: los valores superiores (justicia, belleza, religión). La prioridad, sin embargo, en el tiempo en modo alguno contradice la importancia de la dignidad, ya que son los valores superiores, los que construyen la persona en su más estricta humanidad, son, pues, valores reduplicativamente humanos, ya que perfeccionan lo más humano de los humanos.

Max Scheler denominó altura a la dignidad, nobleza, categoría o elevación honorífica de un valor. Nicolai Hartmann, en íntima relación con la altura, llamó fuerza de los valores a la necesidad o exigencia de los mismos, es decir, que cada estrato del valor sólo tiene sentido si se han vivido los inferiores. Así, es posible construir una escalera desde los valores más bajos (biológicos o corporales) a los 
más altos (religiosos), cuyos peldaños intermedios sean los valores intelectuales, morales y estéticos. En esta gradación cuanto más bajo es un valor tanto más grave es su violación, más obligatoria su realización y menos meritoria su vivencia. Y, a la inversa, cuanto más alto es un valor tanto menos grave es su violación, menor es su obligatoriedad y más meritoria su vivencia.

Tomando como fundamento la altura y la fuerza de los valores, podemos construir la siguiente pirámide en la que se expresa el orden preferencial de la vivencia de los valores, en orden ascendente (fuerza-altura), y en orden descendente (altura-fuerza).

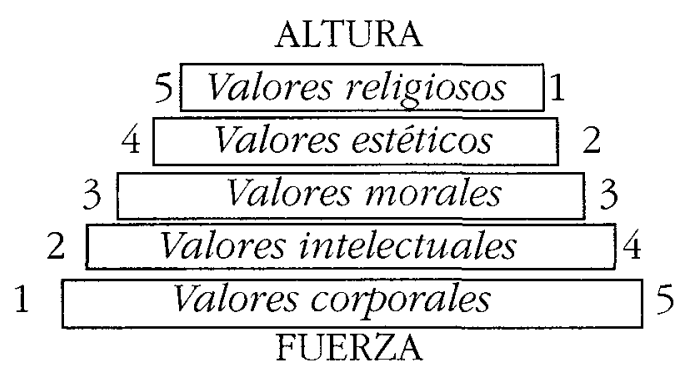

Así, en la realización o vivencia de los valores, es necesario diferenciar y atender a la fuerza o necesidad de los mismos, así como a su altura o dignidad, por cuanto la violación del orden jerárquico puede conducirnos a situaciones de dictadura o imposición de un valor sobre otros más necesarios, minusvalorando o anulando su misma existencia. Inicialmente es preciso atender a los valores inferiores y, desde ellos, ascender a los valores más altos, por cuanto sin la satisfacción de las necesidades más primarias es imposible cualquier otra actividad: intelectual, afectiva, moral o religiosa. Desprovistos de base, los valores superiores no pueden humanamente subsistir despojándose de su valiosidad para convertirse en cinismo, hipocresía o fariseísmo. Buen ejemplo de esta alteración es la figura del fariseo quien, en su intento de vivir los valores superiores (religiosos), se olvida de los inferiores (ayuda al pobre o enfermo); o la del cínico o maquiavélico que sacrifica la ética (justicia) a favor de la estética (amabilidad, belleza); e igualmente quienes anteceden la belleza a la moral o a la salud, por lo que la belleza, al convertirse en tiranía, destruye el orden de la necesidad. Así, la belleza, en sus múltiples sentidos, puede ser valor o antivalor, elemento humanizador o problema inhumano.

\section{LA BELLEZA CORPORAL COMO VALOR Y COMO PROBLEMA}

La belleza ha sido un valor tan antiguo como la filosofía misma, y, en cuanto tal, deseado y deseable, cuya presencia real, como ya afirmó Santo Tomás, nos proporciona deleite: Pulcra sunt ea quae visa placent: son bellas aquellas cosas que son agradables de ver (Tomás de Aquino, I,q.5a.4 ad 1). Ya es significativo al respecto que Afrodita fuese la diosa de la belleza y también del amor, y que su mensajera fuese la Juventud, pues «solo a la belleza le ha caído en suerte ser lo más 
manifiesto y lo más susceptible de despertar el amor" (Platón, 1990a, 250c). Sin embargo, los sentidos de la belleza, como a continuación indicamos, han sido plurales desde el mundo griego - to kalón - a la postmodernidad en la que todo vale, o al menos tiene posibilidad de valer (Gervilla, 1997).

La Paideia griega se elevó desde lo sensible hasta lo eternamente bello. Ya Platón se ocupó del tema to kalón, distinguiendo la belleza en cuanto tal, de las cosas y acciones bellas, siempre imperfectas. Ascenso que expresó en los siguientes términos:

Ésta es justamente la manera correcta de acercarse a las cosas del amor o de ser conducido por otro: empezando por las cosas bellas de aquí y sirviéndose de ellas como de peldaños para ir ascendiendo continuamente [...], de un solo cuerpo a dos y de dos a todos los cuerpos bellos y de éstos a las bellas normas de conducta, y de éstos a los conocimientos bellos, y partiendo de éstos terminar en aquel conocimiento que es conocimiento no de otra cosa sino de la belleza absoluta, que es la belleza en sí (Platón, 1990b, 211c).

Lo Bello, To kalón, es lo que de antemano hace posible la experiencia sensible de las cosas o personas bellas, por lo que el artista es considerado como un demiurgo, un trabajador que reproduce la Idea permanente de belleza en las cosas perecederas. Así nació el arte y su función formativa y educadora, considerándose, en consecuencia, intolerables las obras que imiten el vicio o la indecencia, ya que la belleza y el bien son inseparables (Platón, 1990c, III, 401,b). Lo verdaderamente bello —según el pensamiento aristotélico— es armonía, simetría, regular y cósmico (Aristóteles, 1986, 7, 1450 b 35 y ss.)

Este pensamiento griego perduró hasta el 1750, año en el que el alemán Baumgarten publicó su libro Aesthetica en el que la belleza, ya no reside en las ideas eternas, sino en lo sensible. De este modo, la doctrina de lo bello como perfección sensible, da nacimiento a la estética (aisthetikós: sensación, percepción, conocimiento) la ciencia del arte y de lo bello. Ya la obra de arte no proviene de la belleza eterna, o de la naturaleza, sino de la libertad. "Solo puede llamarse arte —afirmó Kant- a lo que se produce por libertad" (Kant, 1975, parr. 43). Nietzsche consumó la fractura de la tradición griega al afirmar en Gaya Ciencia que la creación estética se mide por su antinaturalismo. Ya no hay mimesis o imitación, sino dominación y conquista, lo bello ahora es la estética de los gustos. Así, la rebeldía contra la tiranía de la Belleza, del Kalós, conduce al anti-arte, al nacimiento de múltiples bellezas sin distinción entre lo Bello y algo bello, por lo que nos quedamos sin saber las razones por lo cual una persona es bella o fea.

La Belleza ha muerto y de sus cenizas han nacido las bellezas, el politeísmo estético, sin fundamento, desacralizado, sensibilizado... Este pluralismo estético, de una mayor fuerza en la actual postmodernidad, hace posible la existencia de cualquier acción o cosa bella y, por lo mismo, también la imposición de un valor sobre los demás. Tal es el caso actual de la tiranía de la belleza sobre otros valores de una mayor urgencia y necesidad, alterando así la fuerza de los valores. 
En estos casos, la fuerza de la belleza es tal que impide la coexistencia de valores corporales de una mayor necesidad y urgencia: alimento, salud o descanso (Gervilla, 2000a, 38-39). Así, la belleza se convierte en antivalor, destructor del orden jerárquico o preferencial, pues - como ya indicamos- no todos los valores valen lo mismo, ni poseen el mismo orden jerárquico o misma primacía de realización. Y cuando hemos de renunciar a unos para poder realizar otros por ser incompatibles circunstancialmente, nunca hemos de sacrificar el valor inferior que nos impida alcanzar el superior. Como ya observó Maslow,

los valores o necesidades guardan una relación mutua en forma evolutiva y jerárquica, de acuerdo con un orden de fuerza y prioridad [...]. Todas estas necesidades básicas pueden ser consideradas, simples escalones en la senda conducente a la auto-realización, en quien se incluyen todas las necesidades básicas [...]. La naturaleza superior del hombre descansa sobre su naturaleza inferior, a la que necesita como fundamento, de tal modo que su defecto provoca el colapso. Es decir, para la mayor parte de la humanidad, la naturaleza superior del hombre es inconcebible sin una naturaleza inferior como base. La mejor manera de desarrollar esta naturaleza superior es subvenir y satisfacer antes la naturaleza inferior (Maslow, 1998, 193-218).

La falta de atención a las necesidades básicas es un problema también moral, bien por la carencia de recursos, bien porque, en la abundancia de ellos, se prefiere la belleza a la salud y fortaleza física, lo que supone un predominio de la estética sobre la ética. Así, nuestro mundo se encuentra hoy dividido entre quienes sufren la debilidad física, mental y afectiva llegando, a veces, hasta la muerte por carecer de alimentos, y quienes sufren las mismas carencias, en la sociedad de la abundancia, por alcanzar los cánones de belleza vigentes. Tal es el caso de la estética cuando ésta, con su fuerza, se impone a la ética, alterando la prioridad de la vivencia.

Los valores estéticos se sitúan en el ámbito de la conveniencia, y nunca en el de la obligatoriedad, por lo que carecer de un determinado valor estético no constituye falta censurable alguna, pues no existe culpa estética. Los valores éticos, por el contrario, son estrictamente obligatorios, por lo que su omisión es ya una culpa. Cada uno puede escoger las actividades estéticas que más le gusten sin obligatoriedad alguna, ya que su valiosidad queda vinculada a cada persona, por lo que no es posible confeccionar la lista de valores estéticos. De gustibus non disputandum. Ello no es posible en el campo de la ética cuyos valores son estrictamente obligatorios (Méndez, 1990). Nadie está obligado a ser gracioso, guapo, a saber cantar o danzar... Es sólo una carencia, que sería mejor no padecerla, pero que en nada impide el desarrollo de la vida estética por otros caminos, pues lo estético nunca debe molestar y siempre agradar: arte, amor, belleza. Ética y estética, pues, no están en igualdad de condiciones en cuanto a la fuerza o prioridad de su realización.

La belleza en oposición al valor ético es un falso valor, una belleza engañosa, y hasta un posible peligro para el hombre y la sociedad. Los valores éticos valen 
en sí mismos, los estéticos valen para nosotros, por lo que los valores estéticos se ponen de moda y pasan de moda, no así en la esfera de lo ético, por lo cual un conflicto entre un valor ético y otro estético nunca es dramático, sí lo es el conflicto entre dos valores éticos (Méndez, 1990). En términos escolásticos los valores éticos obligan semper el pro semper (siempre y para siempre, esto es, nunca se puede omitir el valor o hacer el antivalor); los valores estéticos, sin embargo, obligan semper sed non pro semper (siempre, pero no para siempre, puede omitirse el valor, aunque nunca realizar el antivalor). La ética es más baja y más fuerte que la estética, por lo que el deber-ser estético es menos exigente que el ético.

No se trata de negar el valor de la estética, sino en afirmar que éste sólo es valioso si antes se vive y se respeta la ética, es decir, que el mal como realidad positiva desaparezca de nuestras vidas, pues nunca seremos plenamente felices en lo estético si antes no logramos desaparecer el mal ético. Lo que desvaloriza la estética, y hasta la hace odiosa, es carecer de una base ética (Méndez, 1990). De aquí que estimamos más a una persona, y nos resulta más admirable, en la medida en que posee los valores más altos siempre que previamente realice los más bajos, sin alteración de la pirámide axiológica.

En consecuencia, pues, no basta con afirmar que la educación se fundamente en valores, es imprescindible, junto a ello, clarificar el orden o prioridad de los mismos acorde con la naturaleza de la persona, sujeto de la educación. ¿Qué cuerpo educar? ¿Qué modelo de persona formar? La respuesta a tales interrogantes nos conduce, necesariamente, a la pluralidad jerárquica axiológica y a la diversidad antropológica. El cuerpo es una realidad de la cual se puede renegar, pero nunca negar.

\section{El Clerpo, un VALOR EDLCATIVO DE AHORA Y DE SIEMPRE}

El cuerpo, en sus múltiples sentidos y valoraciones, ha sido siempre sujeto y objeto de especial atención en el ámbito educativo. Las diferencias, a veces sustanciales, se han originado al concretar el sentido del mismo: qué cuerpo educar, dónde y cómo hacerlo. El poder político, con la fuerza de la ley en sus manos, ha determinado, en cada momento histórico, qué cuerpo era preciso educar en la escuela acorde con su ideología ${ }^{10}$. Los cambios legislativos, pues, han orientado sus esfuerzos en justificar la conveniencia del sentido otorgado al cuerpo, según "lo políticamente correcto" por cuanto los valores, además de contenido poseen un sentido direccional. Ello diferencia los distintos modelos educativos sobre el mismo contenido del cuerpo, y sobre el mismo valor de la belleza.

10 Es significativo, al respecto, el contenido de las siguientes leyes educativas, de períodos históricos y políticos diversos: Ley de Educación Primaria ( $B O E, 18$ de julio de 1945); Ley 14/1970, de 4 de agosto ( $B O E, 6$ agosto); Ley Orgánica 1/1990, de 3 de octubre, de Ordenación General del Sistema Educativo ( $B O E, 4$ octubre); Ley Orgánica 10/2002 de diciembre, de Calidad de la Enseñanza (BOE, 24 diciembre). 
Este control institucional pierde fuerza en otros espacios de la educación, cual es la educación no formal e informal. En estos ámbitos los cánones o "normas" del momento se imponen con fuerza a través de los medios de comunicación, presionando, singularmente a la juventud, para vivir un modelo de cuerpo-bello acorde con la actualidad. Así, la escuela paralela coexiste con la escuela oficial, la educación formal con la informal, el colegio con la calle, en la que el cuerpo, siendo el mismo, no es lo mismo. Hoy la educación informal goza de un fuerte poder para inculcar valores, a veces superior a las aulas y textos escolares. Su fuerza se manifiesta con toda virulencia, sobre todo en los más jóvenes. De aquí que toda educación y, por lo mismo, la educación del cuerpo, necesariamente tenga que ocuparse de los valores vigentes fuera del recinto escolar, valores frecuentemente encarnados, vivenciados y visibles en bienes comunes compartidos por la cultura popular. En nuestra sociedad, el valor estético del cuerpo, como ya hemos indicado, ha logrado una fuerza e importancia singular, imponiéndose sobre otros valores de una mayor necesidad. La educación que siempre es un proceso de humanización, un hacerse incorporando valores a la propia existencia ${ }^{11}$, no es una acción axiológica sin más, sino una acción realizada de modo ordenado y armónico, atendiendo a la necesidad y a la altura de los valores. La violación de tales estratos es un atentado al proceso de humanización y, por lo mismo, a toda educación, que ha de ser integral.

\section{Dictadura de la BELLeza y educación INTEGRAL}

El absolutismo estético de la belleza corporal impide el desarrollo armónico e integral de la persona y, por lo mismo, alcanzar la educación integral, esto es, la educación del hombre completo, de todas y cada una de sus facultades y dimensiones. Este deseo de alcanzar, a través de la educación, un hombre completo ha sido y es una aspiración antigua y constante a través de la historia de la educación ${ }^{12}$.

11. Como ya escribió Zubiri, "el hombre, al existir, se encuentra con la tarea principal de tener que hacerse" (Zubiri, 1944, 436).

12. Recordemos al respecto el deseo platónico de dar al alma y al cuerpo, la totalidad de la persona, la máxima perfección y belleza posibles; la Didáctica Magna de Comenio que aspiraba a "enseñar todo a todos", a lograr la "pansofía" o la "pampaideia"; el ideal de Rousseau de formación total, alejada de toda vana erudición y estudio; el proyecto pedagógico marxista de educación integral, propuesto por Marx, para propiciar la formación del hombre polivalente que pudiese ser simultáneamente pastor, pescador, cazador, crítico..., sin someterse a la especialización enajenante que impone la división del trabajo; el ideal de Manjón de cultivar cuantos gérmenes ha puesto Dios en el hombre en su doble naturaleza espiritual y corporal; la exigencia de una educación integral para alcanzar un humanismo integral de Jaques Maritain; la finalidad de la educación de Ismael Quiles, puesta en el desarrollo armónico de todas las cualidades, capacidades o facultades del ser humano en orden a la personalización. También el anarquismo y el liberalismo harán de la educación integral el núcleo central de la revolución social: Bakunin, Paul Robin, Ferrer i Guardia... hacen de la desigualdad en la educación la causa del sometimiento de unos hombres a otros. Sólo una educación completa, que una cultura y trabajo, terminará con la esclavitud. 
Este ideal de integridad o plenitud no se realiza mediante la yuxtaposición o suma cuantitativa de valores, y menos aún con la preponderancia de un valor sobre los demás, sino por medio de la integración e interrelación de los mismos desde la unidad de la persona, pues la educación se realiza en el ser humano y éste es un todo armónico en el desarrollo de su personalidad. La carencia de este sentido integrador nos conduce a la parcialidad o el desarrollo unilateral, situaciones ambas atentatorias contra el desarrollo armónico de la persona. Tales deficiencias son hoy rechazadas entre los pedagogos, así como en los documentos legislativos de ámbito nacional e internacional que, de modo unánime, proclaman la necesidad de la educación integral, lejos de toda tiranía o imposición axiológica ${ }^{13}$.

A nivel, pues, legal lo mismo que pedagógico no es posible una educación de calidad, que no contemple en su programa de acción el desarrollo armónico de todas las potencialidades del ser humano. El problema radica en determinar qué potencialidades, su sentido y preferencias que nos orienten hacia la opción por un concepto determinado de persona. Tarea compleja y difícil, pero necesaria, y anterior a la acción educativa, pues para educar es necesario saber previamente qué educar: contenido, fines, valores y circunstancias.

\section{LA FORMACIÓN O CONSTRUCCIÓN HUMANA: APARENTAR Y SER}

La construcción humana sólo es posible entre los humanos, en unas circunstancias físicas y ambientales de tal fuerza configuradora que su influencia condiciona nuestra formación. Ya Ortega dejó constancia de ello en su famosa frase: "Yo soy yo y mi circunstancia y si no la salvo a ella no me salvo yo" (Ortega y Gasset, 1946-1983, 322). La persona y sus circunstancias se coimplican de tal modo que es imposible su separación, para bien o para mal, pues el ser humano de carne y hueso siempre es situacional. De tales circunstancias no es posible, ni tampoco conveniente, huir, pero sí modificar acorde con el proceso de formación humana, pues las personas y la sociedad no cambiarán — como ya escribió Antonio Machado- mientas no cambien sus dioses.

13. Así, la Declaración Universal de los Derechos Humanos (10-XII-1948) en su artículo 26,2 dice al respecto: "La educación debe tender al pleno desarrollo de la personalidad humana y a reforzar el respeto a los derechos del hombre y de las libertades fundamentales. Debe favorecer la comprensión, la tolerancia, la amistad entre las naciones y todos los grupos sociales o religiosos, así como el desarrollo de las actividades de las Naciones Unidas para el crecimiento de la paz". En el mismo sentido se pronuncia la Constitución Española (31-X-1978): "La educación tendrá por objeto el pleno desarrollo de la personalidad humana, en el respeto a los principios democráticos de convivencia y a los derechos y libertades fundamentales" (art. 27,2). No menos explícita sobre el tema fue la LODE (3-VII-1985) cuando al enumerar los fines de la educación, afirma que pretenderá "el pleno desarrollo de la personalidad del alumno" (art. $2^{\mathfrak{o}}$ ). Y la LOGSE (4-X-1990), recogiendo la legislación precedente, insiste en su Título Preliminar y en los artículos primero y segundo en la necesidad de una educación plena. La reciente LOCE, Ley de Calidad de la Educación (24-XII-2002), entre los derechos básicos de los alumnos, reconoce el derecho aa recibir una formación integral que contribuya al pleno desarrollo de su personalidad» (art. 2, 2.a ). 
Hoy uno de estos dioses es el cuerpo, su apariencia más que su ser. Nuestra sociedad invita a cultivar más el exterior que la interioridad, el poseer más que el ser, la belleza externa sobre la interior. Y las virtudes, aunque no son visibles, por cuanto su bondad radica en el interior, sí son construibles desde la interioridad. Como ya decía el Principito, "no se ve bien sino con el corazón, pues lo esencial es invisible a los ojos" (Saint-Exupéry, 1981, 87). La novedad actual no reside tanto en la necesidad de justificar cambio, cuanto en la dificultad del mismo, debido a la fuerza de las circunstancias, pues la belleza del cuerpo, siendo un valor, no es posible su consecución a cualquier precio, por cuanto su culto extremo, como ya indicamos, conduce al cuerpo-precio en detrimento del cuerpo-dignidad.

Los medios de comunicación, conscientes de tales circunstancias, anteponen la venta publicitaria y consumista del cuerpo-estético a la construcción del cuerpoético y de la formación integral humana. Así, la educación se encuentra hoy frente a una doble dificultad a superar: la lucha contra el "dios" supremo que impide la vivencia de otros dioses, y el esfuerzo por superar las circunstancias que fomentan de este "dios". El ser y el deber-ser, lo que hay como realidad y lo que deseamos como ideal, el gusto animal y la apetencia racional, ha sido y es una lucha permanente, y hasta desigual, en la construcción humana. La educación nunca ha sido un regalo de la naturaleza, sino una conquista de la misma; siempre ha sido una selva que es preciso convertir en jardín, una carrera — "currículo" - en la que sin esfuerzo no es posible llegar a la meta.

Ante esta situación, "Conviene edificar de nuevo la demolida fábrica de la voluntad, para explicar así mejor el comportamiento humano, comprender mejor nuestra situación en el mundo, diseñar mejor lo que desearíamos tener, y encauzar mejor los sistemas educativos" (Marina, 1998, 154). La vida de todo ser humano es, así, una batalla de la cual no es posible huir, sino triunfar o perecer... Y la educación que pretende hacer más persona, a la que ya es por naturaleza, no puede, salvo contradecirse a sí misma, seguir las orientaciones ambientales del culto y comercio del cuerpo, pues ello nos induce a situaciones antihumanas y hasta destructivas, de las cuales sólo es posible escapar basándose en esfuerzo, pues no siempre coincide el bien y el placer, los valores y los intereses, la moda y la educación.

Al esfuerzo Manjón denominó virtud de la fortaleza, pues "da fuerzas para vencer las dificultades y superar los obstáculos que se oponen al bien obrar" (Manjón, 1945, 95). Es, pues, virilidad, valentía, constancia ante el bien, cuya vivencia frecuentemente se presenta conflictiva, en abierta oposición, en cuya lucha siempre uno es el vencedor y otro el vencido. La libertad de los humanos es, así, posibilidad para la liberación y también para la esclavitud, pues la dignidad moral depende de las decisiones de cada uno, ya que el ser humano se hace eligiendo, superando las circunstancias externas físicas y humanas. En palabras de Zubiri, "el hombre como ser viviente está constitutivamente dotado de dos dimensiones: una independencia respecto del medio, y un control específico sobre él» (Zubiri, 1992, 21). 


\section{ORIENTACiONES EDUCATIVAS}

Ante lo expuesto, los educadores no deben ser indiferentes. La educación, en cuanto saber práctico, ha de conocer la realidad del momento para incidir sobre ella con intención de mejora. La situación dictatorial de la belleza corporal, demanda una respuesta reflexiva, crítica y estimulante en orden a la educación integral. Para ello hemos de orientar la voluntad hacia el buen bacer o recto querer, mediante el uso de los elementos y recursos necesarios para ello: conocimiento, estimación y acción.

Conocer la realidad es el primer paso para cambiarla. Ya afirmó Zubiri que «el intelecto es "causa" de la volición. Y precisamente porque la inteligencia puede tener distintas concepciones del bien, es por lo que la voluntad puede ser llevada en distintas direcciones" (Zubiri, 1992, 150). El razonamiento sobre la deshumanización del culto al cuerpo, como hemos indicado, pueden ser el inicio del cambio educativo. Mediante la reflexión crítica se pretende probar, demostrar o persuadir de la maldad de la dictadura estética del cuerpo ${ }^{14}$. No se trata sólo de mostrar - algo que ya hacen por sí los hechos - sino de demostrar, es decir, de dar razones de los mismos y de su situación. Cuando se trata de hechos, la mostración es la prueba de su existencia; sin embargo, la demostración va más allá de los datos, de lo que se muestra o se ve. Se hace, pues, necesario clarificar el entendimiento ante el problema actual, para persuadir sin necesidad de imponer, para convencer sin vencer, pues el convencimiento se orienta hacia la transformación, y, sin embargo, vencer apunta a la destrucción.

Y aunque la voluntad es la dirección inteligente de la conducta (Marina, 1998, 185), el conocimiento, siendo necesario no es suficiente, pues no sólo hay que convencer intelectualmente, sino también lograr el entusiasmo por la vivencia. El conocimiento de algo, a través de la razón, posibilita la estima, pero no siempre conduce a su vivencia. La "lógica del corazón" de Pascal y la "intuición emocional" de M. Scheler han confirmado el carácter peculiar, y a veces irreductible, de las emociones y a la vez su intencionalidad. La vida emocional es un fenómeno íntimo y también social relacionado con la decisión de la voluntad, pues "la voluntad justa es un amor bueno; la voluntad perversa, un amor malon (San Agustín, 1986-1993, XIV, 2).

Sin embargo, conocer y sentir no siempre se orientan en la misma dirección, como sería deseable, más aún en situaciones sociales adversas, cual es la dictadura

14. La crítica forma parte del contenido del mismo razonamiento, que trata de valorar los hechos, de emitir juicios de valor. Criticar, por tanto, es juzgar, discernir, separar lo valioso de lo que no lo es, al modo como lo hace la criba o arnero. La labor de la crítica es, pues, siempre positiva, por cuanto cada cual, desde su personal visión, separa, selecciona e incorpora a su persona aquellos valores o aspectos de un hecho que le hacen más valioso. Mayor importancia reviste aún en las sociedades pluralistas y de crisis permanente, cual es nuestro caso, en las que un constante "bombardeo" informativo y axiológico sobre el cuerpo nos invade diariamente. Sólo es posible escapar a frecuentes parcialidades y contradicciones a través de un conocimiento lo más completo posible y un juicio crítico que nos acerque a la verdad, o al menos, a nuestra verdad, lejos de manipulaciones y adoctrinamiento. 
estética del cuerpo. La armonía del animal ha quedado, así, positivamente rota en los humanos, como ya observó Pascal: "En el hombre hay una guerra intestina entre la razón y las pasiones [...]. Poseyendo una y otra, no puede estar sin guerra, dado que no puede estar en paz con una parte sin hallarse en guerra con la otra. De este modo el hombre se halla siempre dividido y contrario a sí mismo" (Pascal, 1963, 586). La batalla entre la razón y la pasión siempre termina con el triunfo o la derrota de una sobre otra. Este momento siempre es conflictivo, por cuanto no siempre coinciden en la misma dirección la inteligencia y el deber, el bien y el placer, la moda y la educación. Sólo el esfuerzo, en tales situaciones, se presenta como posibilidad del control de los impulsos y, por tanto, de éxito.

El esfuerzo es fuerza, acción energética o volitiva, que nos hace vencer obstáculos para conseguir el fin propuesto. Sin finalidad valiosa el esfuerzo es sólo tensión, lucha ciega e irreflexiva, desgaste inútil de energías. Es, pues, siempre un medio para conseguir algo previamente querido. Y, como todo medio (atendiendo a su etimología latina medium: lo que está en medio entre dos puntos) su función es unir los dos elementos, alcanzando lo deseado (intención + esfuerzo = consecución). Por eso, el medio sin el fin es ilógico e inadmisible racionalmente, pues siempre nos esforzamos por algo valioso, que merece la pena, venciendo, si fuese preciso, los impedimentos para ello.

En consecuencia, pues, el esfuerzo conlleva sacrificio, privación, renuncia a algo que se hace para conseguir algún bien. Hoy, sin embargo, como constata Javier Elzo, en muchos adolescentes españoles existe un hiato, una disociación entre los valores finalistas y los valores instrumentales.

Los adolescentes españoles de finales de los 90 invierten afectiva y racionalmente en valores finalistas, tales como el pacifismo, tolerancia, ecología, etc., y sin embargo presentan grandes fallos en valores instrumentales sin los cuales es imposible su consecución. Me refiero a los déficits que los jóvenes presentan en valores tales como el esfuerzo, la autorresponsabilidad, la abnegación, el trabajo bien hecho, etc. La falta de articulación entre valores finalistas e instrumentales está poniendo de manifiesto la contradicción de muchos adolescentes y jóvenes para mantener una coherencia entre el discurso y la práctica allí donde sea necesario el esfuerzo sin utilidad inmediata (Elzo, 1998, 12-14).

Ser persona educada, quizás hoy más que en otros tiempos, dadas las peculiares características de nuestra sociedad, es una meta difícil, acaso imposible de alcanzar, sin una pedagogía del esfuerzo, pues su presencia se hace necesaria en todas las dimensiones de la educación: intelectual, física, moral, individual, social, etc. No se trata de una mera adaptación al medio, ni de una socialización irreflexiva, ni de formas correctas de urbanidad, sino de formar personas con los conocimientos, actitudes y valores necesarios para hacerse presentes en la realidad sociopolítica con un serio compromiso de mejora. Y ello no siempre es posible sin el esfuerzo, por cuanto el "ser" nos viene dado por la naturaleza, pero "el deber ser" hay que conquistarlo mediante la formación, pues nacemos humanos pero no 
humanizados, sociables pero no socializados, con la posibilidad de ser felices y libres, pero no con la posesión de la libertad y la felicidad. Aprendemos a ser humanos incorporando valores, jerárquicamente ordenados, a nuestra existencia. Es más, la misma libertad humana, el autodominio, la tolerancia o la solidaridad, valores emergentes en nuestra sociedad, pueden quedar anulados o atrofiados sin el hábito del esfuerzo.

En síntesis, pues, de cuanto hemos indicado sobre la dictadura de la belleza, podemos afirmar que la sociedad del bienestar nos ha deparado, junto a la satisfacción de las necesidades básicas, una crisis o cambio de valores con relación al contenido, sentido y jerarquía de los mismos. Ello ha ocasionado, en un sector de la sociedad actual, sobre todo en los jóvenes, una alteración en cuanto a la vivencia de algunos valores, olvidando la necesidad y altura de los mismos. En este contexto se sitúa el culto al cuerpo y la tiranía de la belleza, que dificultan o impiden la formación humana.

La educación, en consecuencia, ha de conocer el problema y su situación para que, de modo reflexivo y crítico, incidir sobre él con la intención de mejora. El principio de este cambio, reside en la persuasión, en convencer y no en vencer, de la necesidad del desarrollo integral y armónico de la persona, más aún hoy en circunstancias ambientales adversas, cuya superación demanda, frecuentemente, la necesidad del esfuerzo como medio.

\section{BIBLIOGRAFÍA}

Altarejos, F. (2002) Dimensión ética de la educación. Pamplona, EUNSA.

ARISTÓteles (1986) Poética, Obras. Madrid, Aguilar.

Baudriltard, J. (1992) Pour une critique de l'économie politique du signe. París, Gallimard.

- (1991) Las estrategias fatales. Barcelona, Anagrama.

Calvo Sagardoy, R. (2002) Anorexia y Bulimia: Guia para padres, educadores y terapeuta. Madrid, Planeta.

CONTRERAs, J. (1993) Antropología de la alimentación. Madrid, Eudema.

Elzo, J. (1998) Jóvenes, noche y diversión: una interpretación sociológica, Misión Joven, 207 (3), 5-12.

ESPIDO FReIRE, L. (2002) Cuando comer es un infierno: confesiones de una bulimica. Madrid, Aguilar.

Gervilla, E. (2000a) Modelo axiológico de educación integral, Revista Española de Pedagogia, 215 (1), 39-58.

- (2000b) Valores del cuerpo educando. Antropología del cuerpo y educación. Barcelona, Herder.

- (1999) El cuerpo como valor educativo: la postmodernidad frente al cristianismo, Teoría de la Educación. Revista Interuniversitaria, 11, 101-125.

- (1997) Postmodernidad y educación. Valores y cultura de los jóvenes (3. a edición). Madrid, Dykinson.

Gual García, P. (2000) ¿Anoréxica yo?, ¿anoréxica mi bija? Bilbao, Desclée de Brouwer.

KANT, I. (1977) Crítica del Juicio. Madrid, Espasa-Calpe. 
Lavelle, L. (1995) Traité des Valeurs (vol. 2º). París, Presses Universitaires.

LIPOVETSKY, G. (2000) La tercera mujer. Barcelona, Anagrama.

- (1990) La era del vacio. Barcelona, Anagrama.

MANJón, A. (1945) El maestro mirando hacia dentro. Granada, Patronato de las Escuelas del Ave María.

Marina, J. A. (1998) El misterio de la voluntad perdida. Barcelona, Anagrama.

Maslow, A. (1998) El hombre autorrealizado. Hacia una psicología del Ser. Barcelona, Kairós.

MÉndeZ, J. M. (1990) Valores estéticos y ascéticos. Madrid, Reyes Magos, 18.

NiETZSCHE, F. (1967) Obras completas. Madrid, Aguilar.

Ortega y Gasset, J. (1946-1983) Obras Completas (vol. $2^{\circ}$ ). Madrid, Revista de Occidente.

PLATÓN (1990a) Fedro, en Obras Completas. Madrid, Aguilar.

- (1990b) Banquete, en Obras Completas. Madrid, Aguilar.

- (1990c) República, en Obras Completas. Madrid, Aguilar.

Pascal, (1963) Oevres completes. París, Éditions du Seuil.

Pérez, P. M.” y Cánovas, P. (2002) Valores y pautas de interacción familiar en la adolescencia (13-18 años). Madrid, Fundación Santa María.

Pérez Alonso, P. M. (1998) Educación estética, en AA.VV. Filosofía de la Educación hoy. Madrid, Dykinson, 377-396.

SaINT-EXupÉRY, A. (1981) El Principito (17ª edición). Madrid, Alianza Editorial.

San Agustín (186-1993) La ciudad de Dios, en Obras Completas. Madrid, BAC.

SCHELER, M. (1941) Ética. Nuevo ensayo de fundamentación de un personalismo ético. Madrid, Revista de Occidente.

Tomás de Aquino (1964) Suma Teológica. Madrid, BAC.

Toro, J. (1996) El cuerpo como delito. Barcelona, Ariel.

ZuBIRI, X. (1992) Sobre el sentimiento y la volición. Madrid, Alianza Editorial.

- (1944) Naturaleza, Historia, Dios. Madrid, Editora Nacional. 